\title{
How Cranial Shapes Led to Contemporary Ethnic Classification: A Historical View
}

\author{
Deniz BELEN \\ Ankara Numune Education and Research Hospital, Department of Neurosurgery, Ankara, Turkey
}

\section{ABSTRACT}

In the medical literature, various ethnic terms such as Caucasian or Mongolian,are sporadically cited to indicate the relationship between certain disorders and the geographical origin of individuals. Few scientists recognize that those definitions stem from a medical thesis written by the German physician Johann Friedrich Blumenbach in 1775 . Through considering cranial shapes, Blumenbach proposed five race varieties including the Caucasian, the Mongolian, the Malayan, the Ethiopian, and the American. While he favored only beauty, his contemporaries reclaimed an intellectuality arrangement among those race types and gave the highest credibility to Caucasian, which therefore, besides defining an ethnicity, has conveyed a discriminatory meaning. The term had been widely used in the medical literature without knowledge of its historical background. Although not commonly used any longer, the Caucasian and similar terms that reflect racial preference should be abandoned in medical text and replaced by more favorable definitions.

KEYWORDS: Cultural history, Medical anthropology, Medical ethics

\section{INTRODUCTION}

"There are no races, only clines."

Frank B. Livingstone

$\mathrm{I}$ n the medical literature, various terms indicating individuals' ethnic or geographical origin such as African-American, Hispanic, Caucasian, etc. are occasionally encountered. Such statements are required for certain conditions that are more common in specific ethnic groups or geographical regions. Knowing the origin of an individual presenting with particular symptoms or findings may evoke an academic inspiration, lead to proper diagnosis quickly, and contribute to the treatment, since drug sensitivity may differ among genomic subtypes. Regarding the last statement, new treatment modalities could also be developed for populations harboring particular diseases. One such well-known example is the familial "cerebral cavernomatosis", seen frequently in people indigenous to South or Meso America. By examining these groups, researchers have explored certain gene mutations that have guided them to search for specific therapeutic options (6).

There is no question that scientists should refrain from using discriminative expressions when specifying any ethnicity. Nonetheless, some authors continue to prefer such terms without knowing their racialist background. One such illreputed term is the Caucasian that has its root in a medical thesis written in 1775 by Johann Friedrich Blumenbach, who suggested the diversity of human race by considering cranial shapes (2). However, his conclusion was later used for spreading scientific racism that has continued until now (13). Neuroscience studies have proved that there is no relationship between cranial shape and intellectuality, as with any other physical characteristic (5). While contemporary ethnic classification originated simply from the qualification of cranial shapes and misused later for scientific racism, this issue may be reconsidered for improvement. In this report, the historical background of such ethnic definitions is presented and discussed, and more suitable terminology is proposed. 


\section{JOHANN FRIEDRICH BLUMENBACH'S THESIS "ON THE NATURAL VARIETY OF MANKIND" AND ITS IMPACT ON SCIENTIFIC RACISM}

J.F. Blumenbach, the German physician, physiologist, comparative anatomist, and naturalist, and the founder of anthropology, was one of the early scientists who dealt with the natural history of human beings and whose work consequently contributed to evolutionary theory (Figure 1). He was born to a middle-class family in Gotha in 1752. After studying medicine at Jena and then Göttingen, he graduated from the latter in 1775 and presented the M.D. thesis De Generis Humani Varietate Nativa (On the Natural Variety of Mankind). In his thesis, he predominantly benefited from the work, Systema Naturae (1758), of Carl Linnaeus, the Swedish scientist and the founder of modern taxonomy (10). Linnaeus had proposed in Systema Naturea a foursome race system based on the combination of the ancient four humors (blood, phlegm, choler, melancholy) and four continents, adding to them the posture of man, and named the traits as the Americanus rubescens, the Europeanus albus, the Asiaticus fuscus, and the Afer (Africanus) niger. Subsequently, he had described the Americanus as "rufus, cholericus, rectus" (red, ready to be inflamed, erect); the Europeanus as "albus, sanguineus, torosus" (white, sanguine, muscular); the Asiaticus as "luridus, melancholicus, rigidus" (yellow, melancholic, plump), and the Afer as "niger, phlegmaticus, laxus" (black, sluggish, relaxed). In his work Linnaeus preferred the definition "Homo variat" instead of race (16).

Blumenbach followed Linnaeus in the manner of four geographical origins. He argued that human race could be again categorized in 4 main traits this time based on cranial patterns and dimensions that more or less resembled Linnaeus's original arrangement. Blumenbach published the second edition one year later with no essential alteration. The third edition was published in 1795; here Blumenbach added one more variety, the Malayan, to the original classification. To reach the conclusion, Blumenbach relied upon 60 skulls that had been collected worldwide. By taking beauty as the basic consideration and evaluating cranial extents, he classified the human race types as the Caucasian (white race, including all Europeans, some Middle Easterners), the Mongolian (yellow race, including all East Asians and some Central Asians), the Malayan (brown race, including Southeast Asian and Pacific Islanders), the Ethiopian (black race, including Sub Saharan), and the American (red race, including American Indians) (Figure 2) $(2,8,10)$.

Ultimately Blumenbach concluded that the Caucasian skull (a Georgian female) was the most beautiful with its picturesque appearance such as having nice-looking symmetry, globular structure, moderate frontal protrusion, and small malar bones when compared with other craniums. He additionally claimed that physical characteristics like skin color and cranial shape could be affected by geography and climate in time, which opinion directed his thoughts to monogenism. Furthermore, by accepting the "degenerative hypothesis" of races, he argued that Adam and Eve were originally Caucasian and other races evolved through degeneration from environmental factors

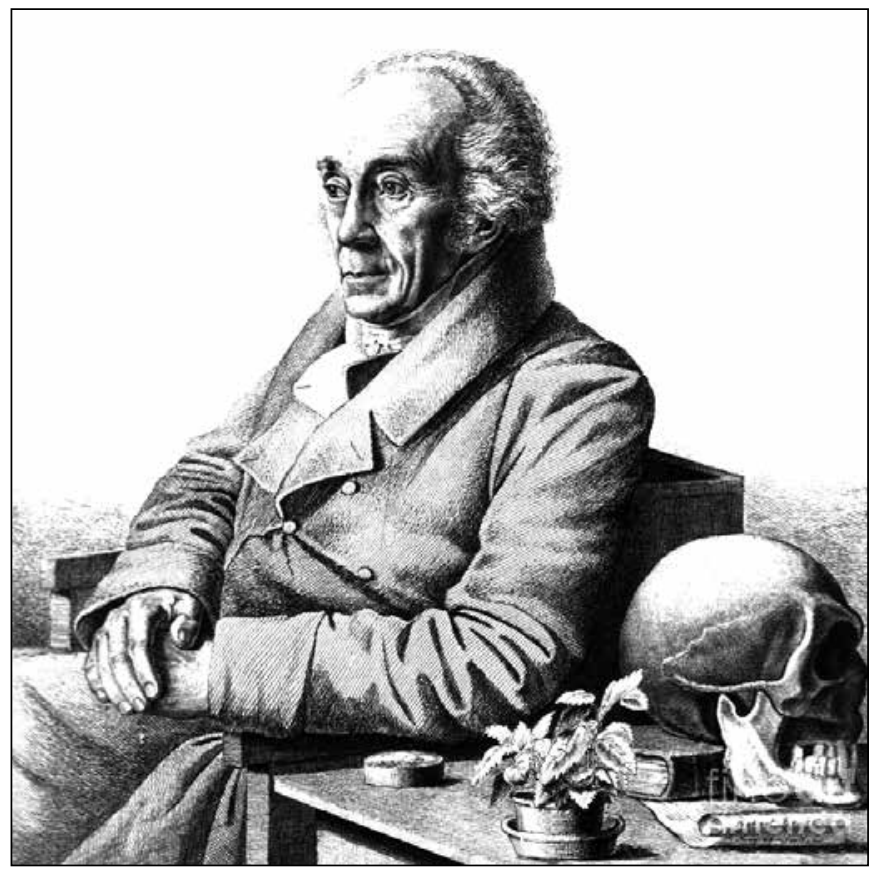

Figure 1: Johann Friedrich Blumenbach (1752-1840).

such as sun and insufficient food. To him, the change of the skin color of the Ethiopian race was the result of strong tropical sun whereas Eskimos had a tawny skin color attributable to cold wind, and so on. He exchanged letters on this topic with Immanuel Kant, who appreciated Blumenbach's theory with little objections. The publication time of Blumenbach's thesis coincided with Thomas Jefferson's Declaration of Independence and Adam Smith's An Inquiry into the Nature and Causes of the Wealth of Nations in 1776, which may give an idea about the prevailing Western attitude toward human races in this era $(2,8,10)$.

Blumenbach was of the opinion that all those race varieties did not differ by means of intelligence. He emphasized that the Ethiopian race was not inferior when compared with other race types and moreover he claimed that it bore excellent natural talents and mental capacities. To prove the latter statement, Blumenbach had collected many books written by African people, an unexpected act for his time (10). He did not consider his "degenerative hypothesis" as racist. However, some of his contemporaries, like the German physicians Christoph Meiners and Samuel Thomas von Soemmering, who were the early champions of scientific racism, took advantage of Blumenbach's concept for their commitment. After conducting autopsies and craniometrical measurements on cadavers of different ethnic origins, both scientists concluded that Africans were an inferior race $(10,11,20)$. From that time forward the term Caucasian, as White European or Arian, was accepted as a superior race and the rest as inferior to it (12). Craniometry had also become a significant method for scientific racism by this time (Figure 3).

As Blumenbach sharply criticized Meiners and Soemmering for their racist approach, his theory lost its positive impact 


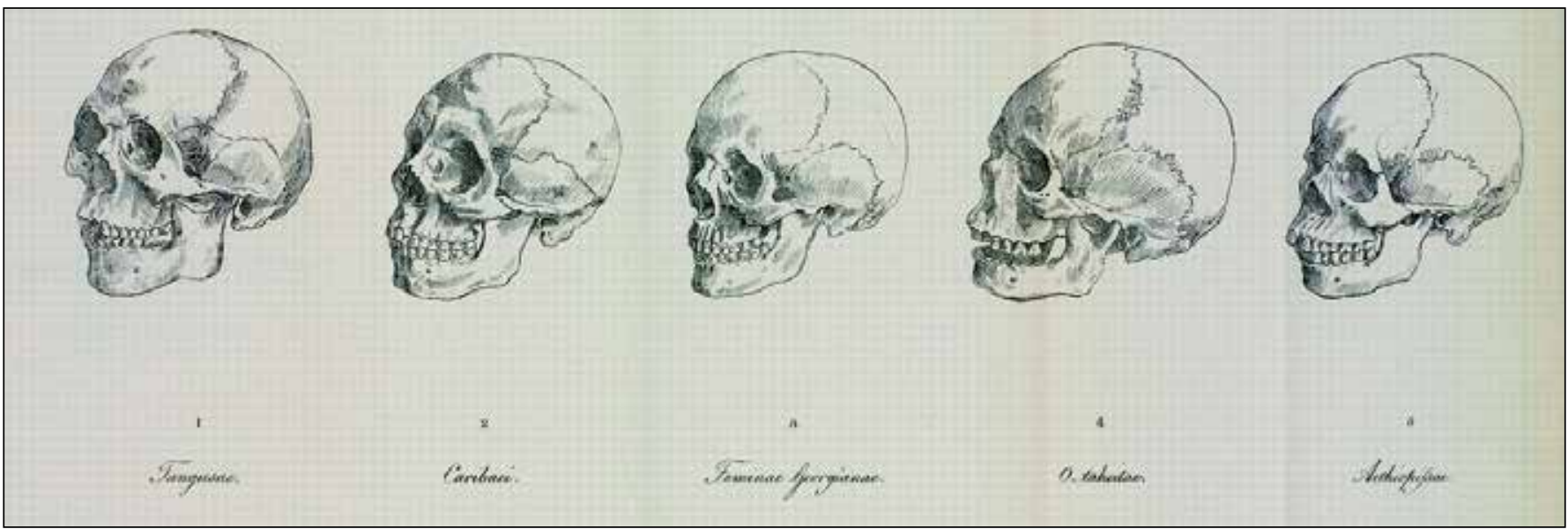

Figure 2: The illustration showing five craniums that first appeared in the third edition of De Generis Humani Varietate Nativa. Blumenbach considered the cranium of the Georgian female (in the center) as "the most beautiful" and named the related ethnic trait as the Caucasian.

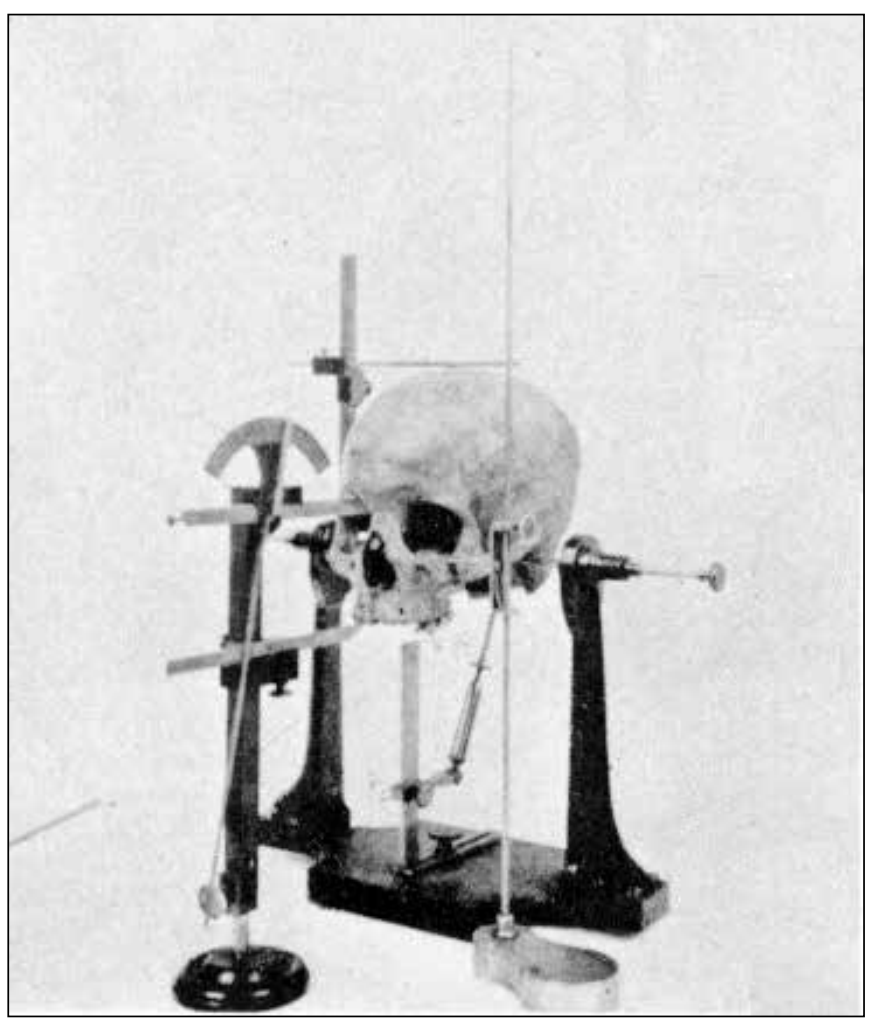

Figure 3: The picture demonstrates the equipment used at the beginning of $20^{\text {th }}$ century for craniometrical methods.

on human studies and fell to oblivion for a few decades (12). Blumenbach died in Göttingen in 1840 leaving opulent medical and biological works behind him. In the following period, his ideas were used to support scientific racism. In this era, the craniometrical methodology was frequently used in human race studies. Blumenbach's work was revived and adopted by many biologists and comparative anatomists in the second half of the nineteenth century who were interested in the origin of races, including William Charles Wells, William Lawrence,
James Cowles Prichard, Thomas Henry Huxley, William Flower, and Charles Darwin (12). During the same period, the physicians Paul Broca and Anders Adolf Retzius from Europe, and Samuel George Morton from the United States followed in the footsteps of Blumenbach and used craniometry for comparative anatomy and also partly for scientific racism (10-12). Race-associated discriminating ideas and related definitions that originated in this period have survived until today though the majority of scientists have strongly opposed them. Even in the recent past, prominent scientists including the Nobel laureates William Bradford Shockley and wellrespected James Watson expressed racist opinions $(1,17)$. The race/ethnicity matter and associated terms have always stayed at the center of those deliberations. Therefore the use of ill-reputed ethnic terms should be reconsidered and discussed in a scientific context whenever possible and it should always be emphasized that there is no more than one human race on earth, that ethnicity has no any relation with intelligence, and that ethnic diversity should be defined by more suitable terms.

\section{- DISCUSSION}

In scientific writing, and especially in the medical literature there is no overall consensus on classifying of race or ethnicity by definitions. The word "race" is being used interchangeably with ethnic variability, national identity, geographic location and cultural customs or incorrectly with distinct human species, as if there were many. In common and medical usage, race could mean dividing Homo sapiens sapiens into six ethnic groups (22). The assertion "human races" on the other hand does not have any scientific basis. Researchers have shown that currently no more than one human race or homo genus exists on earth, that is homo sapiens sapiens, though it embodies a small percentage of genetic material coming from other homo species like long extinct Homo neanderthalensis and also Denisova hominin due to interbreeding $(15,18)$. It is not rational therefore to refer to distinct human races (or species) in scientific writing today and ethnicity, culture or geography may simply be stated. Well-known anthropologist Livingstone 
clearly expressed this issue earlier: "There are no races, only clines exist" (14).

Though social sciences like anthropology, sociology, politics or epidemiology do not refer to old ethnic terminology any longer, a few of those definitions are sporadically cited in the medical literature, such as the Caucasian or the Mongoloid, and also relatively new ones like the Hispanic $(8,21)$. The main reason for expressing ethnic origin in the medical literature is that some diseases are more common in particular geographical regions and moreover a specific ethnic group and genetic background could be more prone to the disorder. Focusing on those populations may contribute to research and also help develop new drugs. Knowing the origin of patients may also be important in the management of the disease. For example, Glucose-6-phosphate dehydrogenase deficiency, which is frequently seen in the Middle East and South Asia, may be complicated by the use of anti-malaria drugs or sulphonamides $(7,8)$. Because all of these considerations, some authors express the ethnic origin of patients who present with unique syndromes.

The West European and North American authors especially favor ethnic descriptions, owing to the multiethnic assembly of their communities. However, some of these terms are unrealistic, long abandoned and more importantly carry a racist meaning, such as the Hispanic and the Caucasian. It is worth to mention that those accounts do not convey any definite meaning in the rest of the world. It is conceivable that most of the global readers have an opinion about the definitions North African, Central Asian, Sub Saharan, West European, Native Oceanian, Native South American and Native North American. Any crossbreed would be stated accordingly, like Native North American-European. If a patient is of West European origin and living in South America (or in South Africa), this could be defined only as West European or an individual indigenous to this continent could be presented as Native South American. Any Sub Saharan origin would be introduced with the same word, not as African American or African European. For continental origin, more specificity can be provided as East, North, or West etc. If needed, unique populations would be indicated with a suffix, like East AsianTuvan (Siberia), Native South American-Quechan (Peru), Sub Saharan-Oromo (Ethiopia) or Native North American-Navajo (the United States). They are well defined and not perplexing, and more notably not discriminating.

On the contrary, the terms like Aborigine, African American, Hispanic, Mongolian or Caucasian do not infer precise definition. Officially, the United States (U.S.) Census Bureau defines five race categories: White or Caucasian, Black or African American, Native American or Alaska Native, Asian, and Native Hawaiian or Other Pacific Islander (19). The term African American was first used in the late sixties following the then liberal public movement with intention to change discriminative labeling. Likewise, the United States government in the early 1970 s during the administration of Richard Nixon adopted the term Hispanic specifying the people who are of Latin America origin (19). Whereas both terms are officially voluntary and self-designated classifications and do not have any literal basis, from that time on they also have found a place in scientific writing. Literally, Hispanic would mean being Spanish or coming from the Iberian Peninsula and African American means coming from any place in the massive continent of Africa. For example, where in the U.S. Census Bureau list could be an individual who comes from North Africa be assigned, African American or Caucasian? In that situation, the term North African corresponds well.

Similarly, the term Caucasian does not convey any clear definition. Does Caucasian mean that an individual comes from a certain region or does it indicate a definite ethnic origin? Caucasia is one of the diverse regions in the World and contains various ethnic groups. Most of the readers actually recognize that Caucasian defines the White European or more plainly Arian ethnicity; still, it does not give any precision due to wide span of this ethnic group. As illustrated, evidently all those deep-rooted definitions do not specify an individual's precise ethnic/geographical origin and should therefore not be used in the medical literature as literal expressions.

While the mentioned deep-rooted ethnic definitions are used in medical literature with no intention of racial overtone, they could still be disrespectful because of the prejudiced past standing behind them. Humanity has always been sensitive to this topic since the slavery/colonial period. Carl Linnaeus first revealed ethnic definitions in 1758 and named the groups after their continental origin. In this classification, Linnaeus considered body structure and skin color as main characters. His descriptions about certain traits were somehow pejorative, though he considered them as human varieties. A few years later, Johann Friedrich Blumenbach introduced comparable ethnic categorization, taking this time cranial shape as the key character. Finally, in 1796 Blumenbach organized ethnicity in 5 groups and considered the Caucasian as the most beautiful. More importantly, he claimed that all other traits had evolved from the Caucasian. Some contemporary scientists accepted both considerations as superiority, although Blumenbach did not mention any mental capacity difference among traits. The supporters of scientific racism have stated the Caucasian as the superior ethnic group since then. Social scientists currently express the situation openly: "The idea of a hierarchy of races was driven by an influential, secular, scientific discourse in the second half of the eighteenth century and was rapidly disseminated during the nineteenth century" (3). Craniometrical methods have been frequently used for supporting those discriminatory ideas that have survived in various scientific fields until today. Studies have shown that intelligence does not have any relationship with cranial shape or ethnicity $(4,5,9)$.

\section{- CONCLUSION}

History has shown us that Caucasian and similar definitions are evidently reminiscent of racial thinking. Authors should therefore abandon the use of old and biased ethnic definitions. Social sciences have succeeded in doing so, why not the biological sciences? 


\section{- REFERENCES}

1. Bhattacharya S: "Stupidity should be cured, says DNA discoverer", New Scientist News Service, February 28, 2003. Accessed: December 10, 2015. Available from: https://www. newscientist.com/article/dn3451-stupidity-should-be-curedsays-dna-discoverer

2. Bhopal R: The beautiful skull and Blumenbach's errors. BMJ 335:1308-1309, 2007

3. Brown D, Webb C: Race in the American South: From Slavery to Civil Rights $1^{\text {st }}$ ed. Edinburgh, Edinburgh University Press, 2007

4. Bruner E: Cranial shape and size variation in human evolution: Structural and functional perspectives. Childs Nerv Syst 23: 1357-1365, 2007

5. Bruner E, Martin-Loeches M, Burgaleta M, Colom R: Midsagittal brain shape correlation with intelligence and cognitive performance. Intelligence 39:141-147, 2011

6. Choquet H, Pawlikowska L, Nelson J, McCulloch CE, Akers A, Baca B, Khan Y, Hart B, Morrison L, Kim H: Polymorphisms in inflammatory and immune response genes associated with cerebral cavernous malformation type 1 severity. Cerebrovasc Dis 38: 433-440, 2014

7. Doyle JM: What race and ethnicity measure in pharmacologic research. J Clin Pharmacol 46:401-404, 2006

8. Freedman BJ: Caucasian. BMJ 288:696-698,1984

9. Gómez-Robles A, Hopkins WD, Sherwood CC: Increased morphological asymmetry, evolvability and plasticity in human brain. Proc Biol Sci 280:1-9, 2013

10. Gould SJ: The Mismeasure of Man. $2^{\text {nd }}$ ed. New York: WW Norton \& Company, 1996
11. Harris $M$ : The rise of anthropological theory: A history of theories of culture. Lanham, MD: Rowman \& Littlefield, 2001: 84-85

12. Isaac B: The invention of racism in classical antiquity. $1^{\text {st }}$ ed. Princeton NJ: Princeton University Press, 2006

13. Keita SOY, Kittles RA: The persistence of racial thinking and the myth of racial divergence. Am Anthropologist 99: 534-544, 1997

14. Livingstone FB, Dobzhansky T: On the non-existence of human races. Curr Anthropol 3:279-281,1962

15. Lohse K, Frantz LAF: Neandertal admixture in Eurasia confirmed by maximum likelihood analysis of three genomes. Genetics 196:1241-1251, 2014

16. Morris MJ, Berwick L: Was Linnaeus a racist? In: The Linnaean Legacy: Three Centuries after His Birth, a Forum for Natural History. London: Linnean Society of London (The Linnean Special Issue No. 8), Burlington House, Piccadilly, 2008

17. Pearson R: Shockley on eugenics and race: The application of science to the solution of human problems. $1^{\text {st }}$ ed. Washington, DC: Scott-Townsend Publishers, 1992:15-49

18. Pennisi E: More genomes from Denisova Cave show mixing of early human groups. Science 340:799, 2013

19. The United States Census Bureau: http://www.census.gov/ population/race/. Accessed: December 10, 2015

20. Thiel U: Meiners, Cristoph. In: Haakonssen K (ed). The Cambridge History of Eighteenth-Century Philosophy, Vol: 2, Cambridge, Cambridge University Press, 2012: 1203

21. Whaley AL: Ethnicity/race, ethics, and epidemiology. J National Med Ass 95:736-742, 2003

22. Witzig R: The medicalization of race: Scientific legitimization of a flawed social construct. Ann Intern Med 125:675-667, 1996 